Supplement of Atmos. Chem. Phys., 16, 8431-8446, 2016

http://www.atmos-chem-phys.net/16/8431/2016/

doi:10.5194/acp-16-8431-2016-supplement

(C) Author(s) 2016. CC Attribution 3.0 License.

(c) (i)
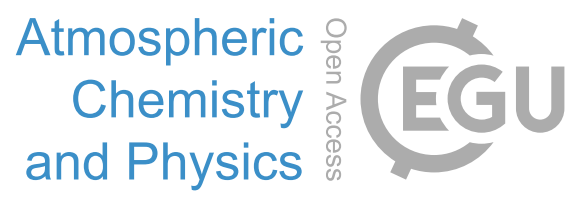

Supplement of

\title{
Measurements of non-volatile aerosols with a VTDMA and their correlations with carbonaceous aerosols in Guangzhou, China
}

Heidi H. Y. Cheung et al.

Correspondence to:

The copyright of individual parts of the supplement might differ from the CC-BY 3.0 licence. 


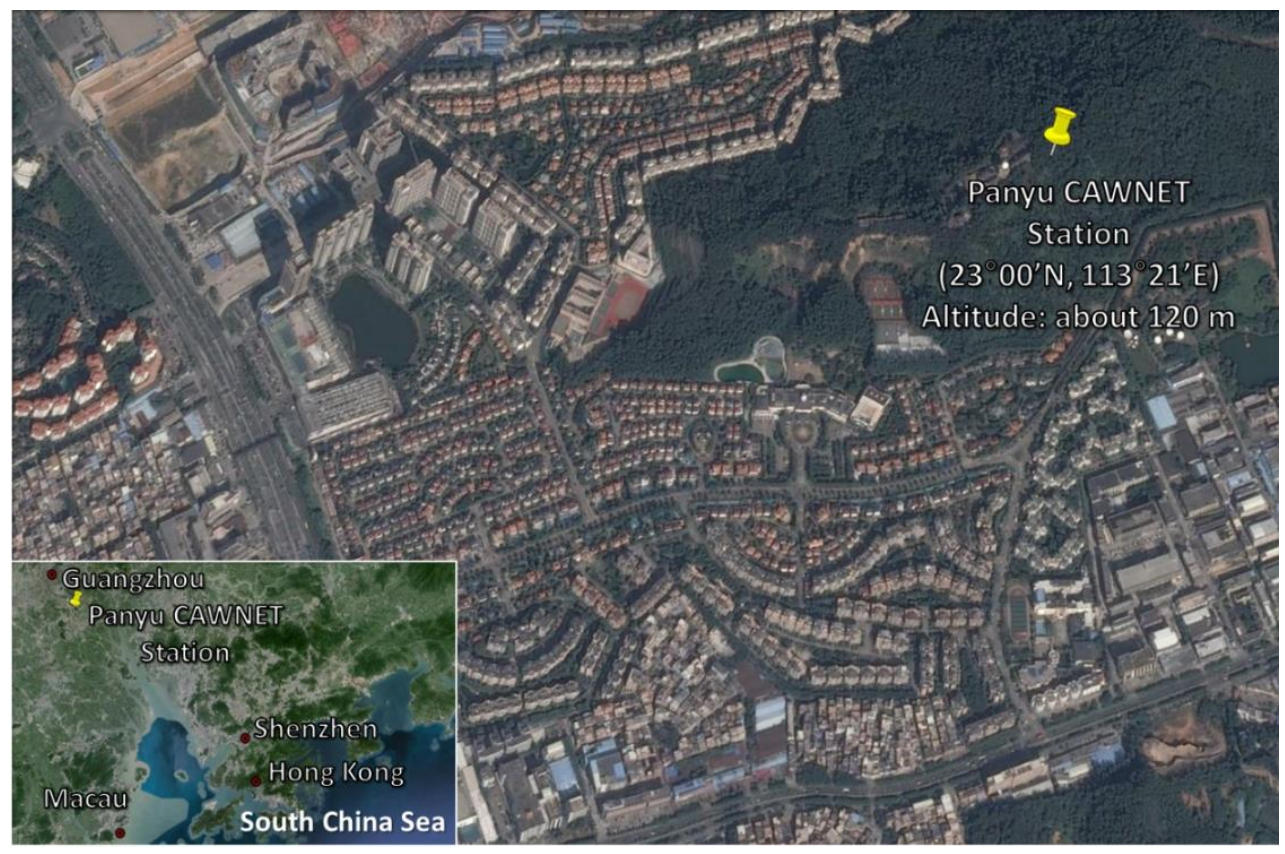

Fig. S1. Location of the measurement site. 


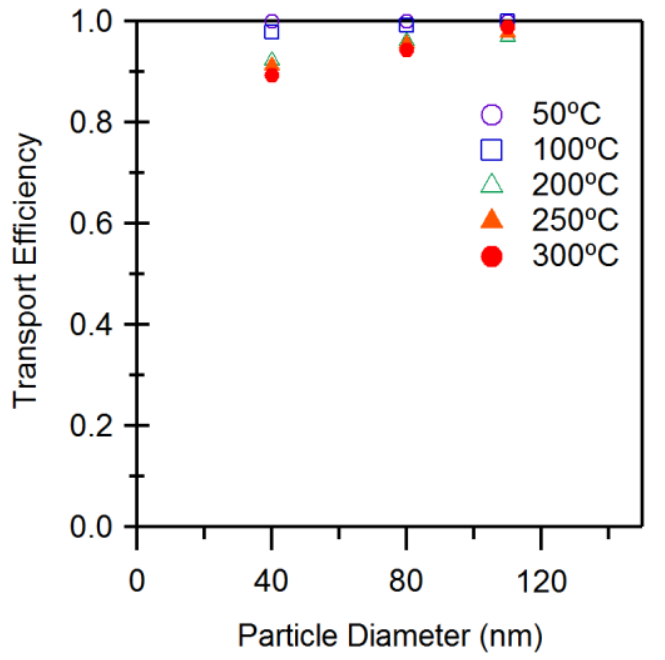

2 Fig. S2. Transport efficiency of $\mathrm{NaCl}$ in the VTDMA as a function of particle diameter and 3 heating temperature.

4

$\square$ Cluster 1 (Coastal, NE) $\square$ Cluster 2 (Maritime, NE/E) $\square$ Cluster 3 (Continental, NE) $\square$ Cluster 4 (Continental, NW) $\square$ Cluster 5 (Continental, NW) $\square$ Cluster 6 (Continental, NW)
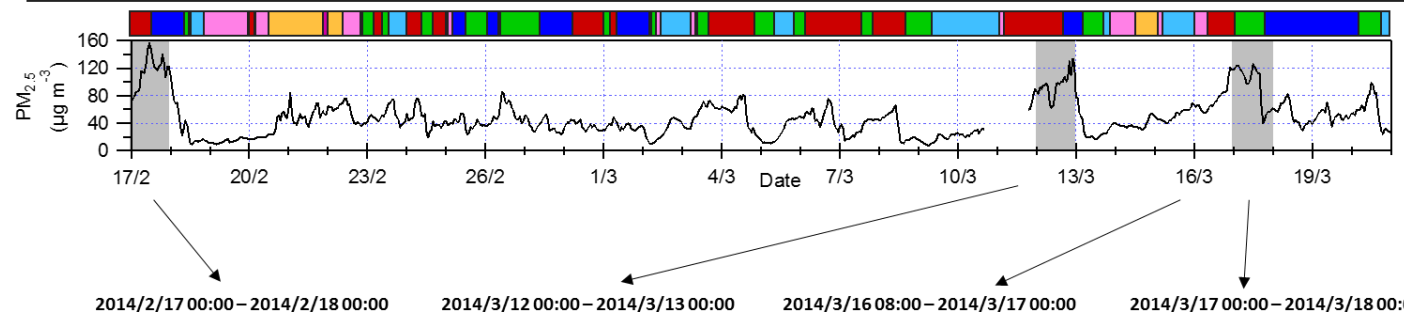

2014/2/1700:00-2014/2/18 00:00 (Local time, UTC+8)

2014/3/12 00:00-2014/3/1300:00 2014/3/1608:00-2014/3/17 00:00 2014/3/17 00:00-2014/3/1800:00 $1 \mathrm{~h}$ interval $1 \mathrm{~h}$ interval $1 \mathrm{~h}$ interval $1 \mathrm{~h}$ interval
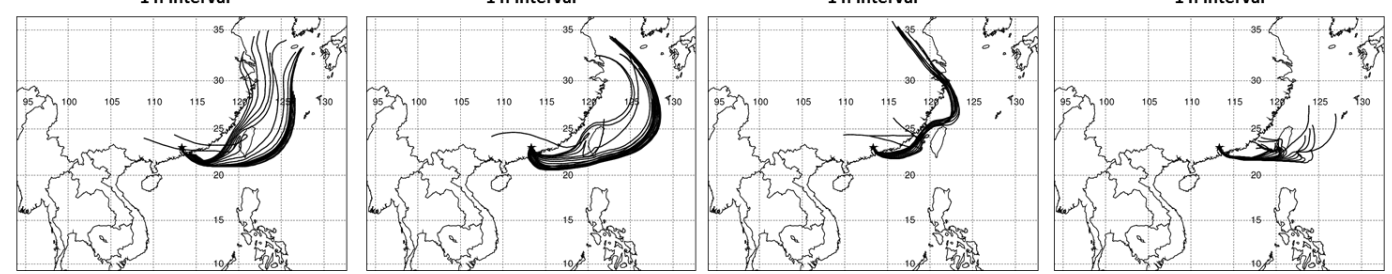

6 Fig. S3. Time series of $\mathrm{PM}_{2.5}$ concentrations and $72 \mathrm{~h}$ back trajectories at hourly intervals on $7 \quad 17$ Feb, 12, 16 and 17 Mar 2014. 

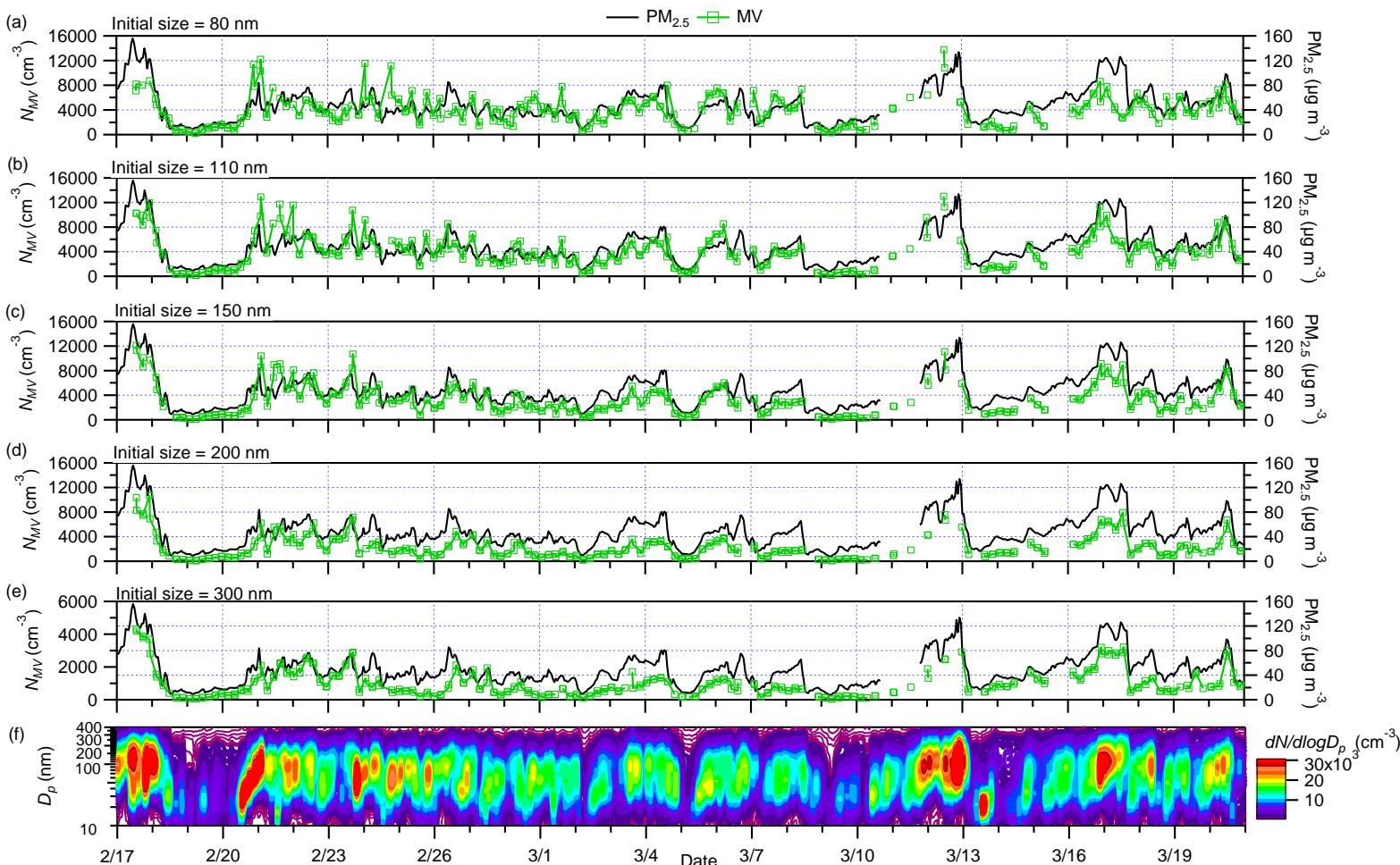

2 Fig. S4. (a-e) Time series of number concentrations of MV particles having initial diameters of $380 \mathrm{~nm}$ to $300 \mathrm{~nm}$ and (f) particle number size distributions during the campaign. Time series of $4 \quad \mathrm{PM}_{2.5}$ concentrations are plotted on the right axis in (a) to (e). 

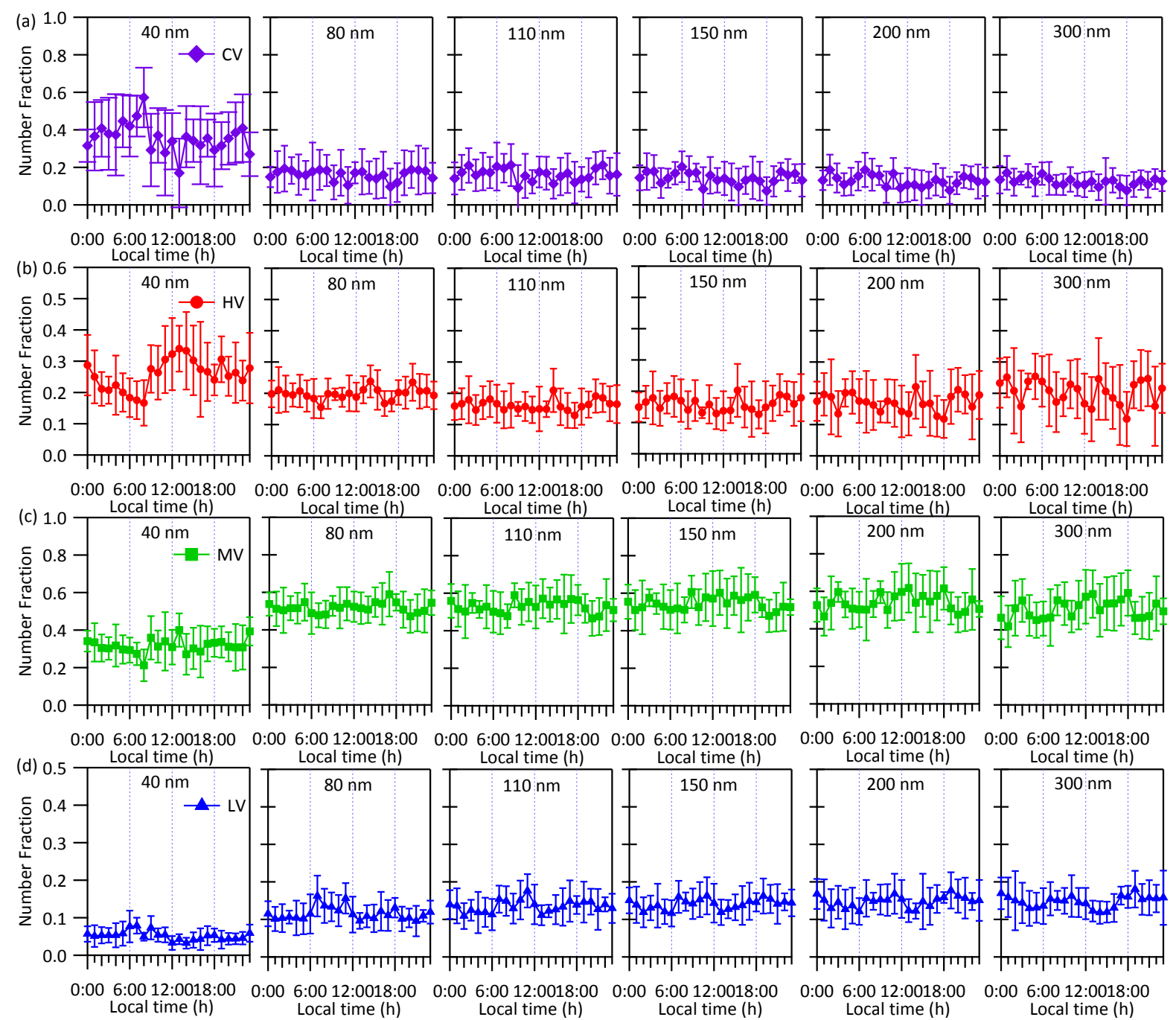

2 Fig. S5. (a-d) Diurnal variations in the number fractions of CV, HV, MV and LV particles

3 having (from left to right) the six selected diameters ranging from $40 \mathrm{~nm}$ to $300 \mathrm{~nm}$. Error bars

4 represent one standard deviation. 